\title{
A Formação do Professorado da Área de Ciência da Computação no Brasil: uma análise documental da pós-graduação stricto sensu
}

\author{
Pauleany S. Morais ${ }^{1,2}$, Jean C. S. Rosa ${ }^{2,3}$, Ecivaldo Matos ${ }^{2}$, \\ Marlo Souza $^{2}$, Luana R. Carneiro ${ }^{2}$ e Murilo V. F. S. Souza ${ }^{2}$ \\ ${ }^{1}$ Campus de Educação a Distância - Instituto Federal do Rio Grande do Norte (IFRN) \\ Natal - Rio Grande do Norte - Brasil \\ ${ }^{2}$ Departamento de Ciência da Computação - Universidade Federal da Bahia (UFBA) \\ Salvador - Bahia - Brasil \\ ${ }^{3}$ ITI/LARSYS - Madeira Interactive Technologies Institute (M-ITI) \\ Funchal - Portugal \\ pauleany.moraiseifrn.edu.br, \{jean.rosa, ecivaldo, \\ msouzal\}@ufba.br, \{luarc99, mvf.souza17\}@gmail.com
}

\begin{abstract}
The discussion about teaching and learning processes has been the subject of research in Computer Science (CS) in Brazil and abroad. Teacher training in CS for higher education should also be thematic of research and action. In this sense, this paper presents an expansion in the scope of an initial research, presented previously, with a quantitative documentary analysis of the master and doctoral courses of the Brazilian CS area. As a result, the emphasis is placed on research to the detriment of university teacher training at master's and doctoral courses, which is contrary to the first objective of the Brazilian post-graduation stricto sensu given by the Parecer MEC/CESu no. 977/65.
\end{abstract}

Resumo. A discussão sobre os processos de ensino e de aprendizagem tem sido tema de pesquisa em Ciência da Computação (CC) no Brasil e no exterior. A formação docente em CC para o ensino superior também deve ser temática de investigação e ação. Nesse sentido, este artigo apresenta uma ampliação no escopo de uma pesquisa inicial, apresentada anteriormente, com uma análise documental quantitativa dos cursos de mestrado e doutorado acadêmicos da área de CC do Brasil. Como resultado observa-se a ênfase dada à pesquisa em detrimento da formação do docente universitário a nível de mestrado e doutorado, o que contraria o primeiro objetivo da pós-graduação stricto sensu brasileira dado pelo Parecer MEC/CESu $n^{o}$ 977/65.

\section{Introdução}

Os desafios da formação docente vêm instigando inúmeros estudos acadêmicos, particularmente no que se refere a atuação do professor universitário bacharel no Ensino Superior. De um modo geral, as universidades têm uma significativa responsabilidade de preparar os profissionais que atuarão na sociedade, inclusive para além da aquisição de 
conhecimentos técnico-científicos especializados, necessita, ainda, preocupar-se com valores éticos e de compromisso social.

[...] formar profissionais competentes e sintonizados com as demandas do mundo atual, que tenham senso de justiça social e uma identidade profunda com a cidadania democrática, é tarefa que exige muito mais desses professores do que repassar os conteúdos de sua área de especialização stricto sensu [Pimenta e Almeida 2011, p. 07].

Diante da dimensão do papel social da universidade, tem-se a necessidade de trazer uma reflexão sobre a formação de seus docentes e a institucionalização de uma Pedagogia Universitária. Vale salientar, que a atuação docente vem superando a perspectiva vocacional, bem como a mera indução de transposição de conhecimentos técnico-científicos em uma dada sala de aula. O processo de ensinar em qualquer modalidade exige ações muito mais complexas do que apenas domínio de dada área do conhecimento. Mostra-se a missão da universidade em manter os profissionais docentes em intensa sintonia com as necessidades sociais do mundo do trabalho em seu amplo sentido (teórico e político).

Nesse contexto, se faz necessário refletir sobre o papel histórico da universidade para a formação dos profissionais, considerando, Santos [2011], Luckesi et al. [2012] e Imbernón [2012]. Além disso, discute-se sobre a relevância da formação docente universitária, abordando a concepção de autores que recebem destaque tais como: Cunha [2006]; Pimenta e Anastasiou [2014]; Almeida [2012], Soares e Cunha [2010], Pimenta e Almeida [2011]; Imbernón [2009]; Imbernón [2011]; Pimenta [2012]; Tardif [2012]. De maneira específica as produções de Massa [2015] e Massa e D’Ávila [2013] tratam da formação didático-pedagógica do docente da área de Ciência Computação no Ensino Superior e relata suas limitações no exercício da docência.

Esse trabalho apresenta uma reflexão sobre a necessidade de formação docente no Ensino Superior e o papel da universidade enquanto lócus dessa formação, tratando especificamente da análise dos Programas de Pós-Graduação (PPG) em Ciência da Computação no Brasil. Nessa perspectiva, serão apresentados resultados de uma análise documental sobre os objetivos, disciplinas e atividades para a formação docente dos cursos de pós-graduação strictu sensu da rede universitária brasileira. Nesse sentido, este artigo apresenta uma expansão da pesquisa apresentada por Morais et al. (2018).

O artigo está dividido em seis seções, sendo a próxima seção destinada a tratar sobre o papel da universidade na formação do docente do ensino superior; a Seção 3 apresenta uma discussão argumentativa sobre a necessidade da formação didático-pedagógica dos docentes do ensino superior. A metodologia da análise documental efetuada na pesquisa é o tema da Seção 4 e, por sua vez, os resultados da metodologia são apresentados na Seção 5. Por fim, a Seção 6 apresenta as considerações finais da pesquisa e os trabalhos futuros.

\section{Papel da Universidade na Formação Docente Universitária}

Para compreensão ampla do papel da atuação docente é relevante conhecer sua origem de significado. De acordo com Soares e Cunha [2010] a palavra docência se origina do latim "docere", traduzida em ensinar e sua ação, também, vem do latim, com o termo "discere" que representa aprender. Desse modo, a docência significa um elo de duas 
vias entre o ensinar e o aprender. A docência enquanto exercício do magistério envolve todos os aspectos que perpassam a aprendizagem. No ensino superior, à docência possui características peculiares em que as principais atividades se centram em atuação no magistério e em pesquisas [Soares e Cunha 2010]. Diante disso, a universidade é um significativo lócus de formação tanto para seus profissionais quanto para a sociedade.

A universidade dentro da lógica de "detentora do conhecimento" pouco direcionou seus esforços em promover uma formação docente articulada às especificidades do ensino superior durante longos anos. Nesse caso, é imprescindível compreender as especificidades da aprendizagem do adulto, baseada na interlocução de expectativas, interesses e necessidades entre os sujeitos envolvidos. É preciso reconhecer a relevância da interatividade como um mecanismo essencial ao exercício da docência. Outra peculiaridade na aprendizagem do adulto no ensino superior será promover estímulos para engajamento consciente e voluntário, mesmo considerando que na fase de ingresso na universidade o discente ainda pouco reconhece elementos essenciais da sua futura atuação profissional [Soares e Cunha 2010].

Nesse contexto, Imbernón [2012, p. 14] relata que "o professor universitário deve conscientizar-se da necessidade da didática de sua matéria para melhorar sua relação com a disciplina, com a docência e com os alunos". Necessita, ainda, romper com as rotinas aprendidas pelo empirismo elementar da experiência subjetiva e superar a Síndrome da Reprodução Universitária citada por Imbernón [2012], pois pouco considera os conhecimentos prévios oriundos da própria comunidade por meio dos alunos.

O contexto da docência universitária se configura de maneira muito mais complexa, pois apresenta-se como um espaço de conexão de conhecimentos, subjetividades e culturas, o que requer um conteúdo científico, tecnológico ou artístico bem mais especializado devido a formação necessária a um profissional [Soares e Cunha 2010 , p. 28]. A formação do professorado em âmbito universitário se torna uma necessidade para o exercício de reflexões mais amplas diante da compreensão crítica da profissão que atua e o contexto mais amplo o qual se insere.

\section{Necessidade da Formação Docente Universitária}

De maneira mais ampla se faz necessário compreender como se constitui os saberes ao exercício da docência. Tardif [2012, p. 54] define o significado do saber docente como "saber plural, formado de diversos saberes provenientes das instituições de formação, da formação profissional, dos currículos e da prática cotidiana”. Nesse sentido, é essencial na construção dos saberes docentes uma formação qualificada em instituições educacionais, que mobilizem conhecimentos referentes ao ato de ensinar e de aprender.

Tardif [2012] delimita uma caracterização construída a partir dos próprios docentes e dos saberes que eles utilizam, de forma afetiva em sua prática, quais sejam: saberes da formação profissional voltados às ciências da educação (teorias e métodos); saberes disciplinares (referentes aos saberes em cada área do conhecimento); saberes curriculares (selecionados e categorizados pelas instituições escolares); e saberes experienciais (constituídos em sua essência na base do trabalho cotidiano). Quando se trata da prática docente, deve-se preparar um profissional considerando sua dimensão científica, técnica, tecnológica, pedagógica, cultural e humana. 
Os saberes docentes são instituídos ao longo de experiências formativas teóricas e práticas do professorado e no transcurso desse período podem ser constituídos em saberes pedagógicos. Vale salientar que saberes pedagógicos: "são aqueles que provêm da formação docente e do exercício da docência e dizem respeito às habilidades, conhecimentos e atitudes mobilizados como respostas às situações do cotidiano escolar" [D’Ávila 2013, p. 25]. Por isso, a constituição dos saberes docentes universitários deveria ser uma busca incessante da universidade para promoção da formação qualificada dos profissionais que circulam na sociedade.

No que concerne à formação docente, Cunha [2006, p. 25-26] aprofunda uma reflexão sobre a constituição dos saberes docentes universitários, descrevendo:

- os saberes relacionados com o contexto no qual se desenvolve a prática pedagógica, que implica a compreensão do papel da universidade na construção do Estado democrático, bem como das políticas que envolvem as instituições;

- os saberes relacionados com a ambiência da aprendizagem, que envolvem o conhecimento das condições de aprendizagem de pessoas adultas e das múltiplas possibilidades que articulam conhecimentos e prática social e aos caminhos de integração no processo de aprendizagem do desenvolvimento cognitivo, afetivo-emocional, de habilidades e de atitudes;

- os saberes relacionados com o contexto sócio histórico dos estudantes, que se traduzem em habilidades de compreensão da condição cultural e social dos estudantes, de estímulo às suas capacidades discursivas e de recomposição de suas memórias educativas, favorecendo uma produção do conhecimento articulada, de forma autobiográfica, e a afirmação de sua identidade social, cultural e pessoal;

- os saberes relacionados ao planejamento das atividades de ensino, envolvendo as habilidades de delinear objetivos de aprendizagem, métodos e propostas de desenvolvimento de uma prática pedagógica efetiva, à capacidade de dimensionar o tempo disponível, em função da condição dos estudantes e das metas de aprendizagem e ao domínio do conhecimento específico de forma a situá-lo histórica e conjunturalmente e a estabelecer relações com outros conhecimentos;

- os saberes relacionados com a condução das aulas nas suas múltiplas possibilidades, que pressupõem a condição do professor de ser o artífice, junto os estudantes, de estratégias e procedimentos de ensino que favoreçam uma aprendizagem significativa, ancorada nas estruturas culturais, afetivas e cognitivas dos estudantes;

- os saberes relacionados com a avaliação da aprendizagem que exigem um conhecimento técnico e uma sensibilidade pedagógica que permite, ao professor, a identificação das estratégias avaliativas que melhor informem sobre a aprendizagem dos estudantes, a partir da retomada dos objetivos previstos e da trajetória percorrida. Os saberes relacionados com a avaliação pressupõem, ainda, um posicionamento, ainda, um posicionamento valorativo sobre os objetivos em questão e a capacidade de comunicar à avaliação aos estudantes. 
A constituição desses saberes deveria ocorrer em cursos de pós-graduação, bem como no transcurso da atuação no exercício da profissão. Almeida [2012] esclarece que docência universitária se caracteriza em três dimensões: profissional, pessoal e organizacional. A primeira refere-se aos elementos que definem a sua formação (inicial e continuada) com a construção de sua identidade docente. O segundo aponta as relações de envolvimento e compromisso com a docência que auxiliaram ao docente a enfrentar os desafios ao longo da carreira. E por último a organizacional está direcionada às condições de organização, condução e remuneração do trabalho, bem como o nível a serem alcançados em atuação. Essas dimensões caracterizam a configuração do "ser docente" no Ensino Superior e somente pode ser articulada em diversos processos formativos ao longo de sua carreira para a constituição de sua identidade com domínio de elementos teóricos e contextuais da atuação profissional.

Além disso, a ação docente no Ensino Superior, principalmente em cursos de predominância das áreas de uso excessivo da racionalidade científica tem a perspectiva de transpor as suas ações de postura técnica à docência. Nesse caso, pouco consegue utilizar características essenciais da profissão docente como a imprevisibilidade, a singularidade, o conflito e a instabilidade [Pimenta e Anastasiou 2014]. Por consequência, a ausência de formação docente inicial e continuada em diversas áreas compromete reflexões mais amplas do fazer docente ao longo de sua trajetória acadêmica.

Por isso, pode-se destacar a necessidade da capacidade reflexiva em grupo para o desenvolvimento da formação docente. Desse modo, a formação docente vai além da atuação técnica, pois envolve um processo coletivo que pode auxiliar a definição de ações e decisões relevantes ao ato educativo. A ação docente não pode ser considerada uma mera atualização científica, pedagógica e didática. Deve, anteriormente, ser um movimento de construção de espaços de participação, reflexão e formação para que as pessoas aprendam e se adaptem para poder conviver com a mudança e a incerteza. Precisa ser dado ênfase ao processo de aprendizagem das pessoas e as possibilidades de tornar o ensino um ato real e significativo [Imbernón 2011].

Na docência universitária, vivencia-se outra limitação na atuação docente: a ênfase rigorosa dada a pesquisa. Parece que, na carreira docente universitária, o campo da pesquisa apresenta-se como estruturante da profissão no processo de construção de conhecimentos. Em contrapartida, a docência é considerada de baixo prestígio acadêmico e social, como expressão de socialização e de difusão do conhecimento [Corrêa et al. 2011]. Mostra-se a necessidade de avançar na perspectiva de compreensão das dimensões da atuação do professor no ensino superior e não apenas foco em sistemas de avaliação que mensuram apenas a atuação do professor como pesquisador e não como docente de uma maneira mais ampla.

A constituição da identidade do professorado refere-se a dimensões muito mais amplas do trabalho docente em que é preciso perceber como interage com os outros, com o contexto, suas experiências de vida e como se articulam com suas atividades profissionais. Significa privilegiar uma formação baseada na reflexividade para o docente analisar o que são ou que desejam ser e o que se faz e como se faz [Imbernón 2009, p. 75]. Um docente reflexivo deve ter como foco de análise suas experiências vivenciadas como docente, sabendo como se constitui os conhecimentos por meio da 
ação [Pimenta 2012]. Significa introduzir mecanismos reflexivos em que o professor se torna um pesquisador da sua própria prática em ação.

Os PPG devem ser um lócus privilegiado de formação à docência universitária em que são sistematizados conhecimentos teóricos e instrumentais para condução de pesquisas, e geralmente, não evidenciam formação voltada aos processos de ensino e de aprendizagem [Pimenta e Almeida 2011]. É preciso superar essa superposição da pesquisa no ensino superior e valorizar outras dimensões da atuação docente. O ensino superior ainda vivencia limitações no que concerne a caracterização da formação do professor universitário para atuação profissional mais ampla, considerando a tríade ensino, pesquisa e extensão.

De maneira mais ampla, deve-se considerar que todo processo educacional exige do professor a compreensão de seu papel de mediador no sentido de promover a internalização de determinados conhecimentos por parte do aluno. Precisa saber oferecer aos seus alunos condições educacionais de realização qualificada do ato de conhecer. Com efeito, a “[...] mediação pode assumir diferentes sentidos. Um deles diz respeito à harmonização de conflitos entre interesses diferentes entre si, com o objetivo de diminuir as diferenças, de unificar as forças ou de equilibrá-las" [Matos 2013, p. 79]. Nessa conjuntura, a mediação configura-se como possibilidade de harmonizar os interesses no ato de conhecer no interior do processo educacional em que o docente precisa orientar as ações necessárias aos processos de ensino e de aprendizagem.

$\mathrm{Na}$ área da Ciência da Computação, o professor universitário, devido a formação inicial em bacharelado, tem seu percurso acadêmico em ensino ou pesquisa instituído por meio de cursos de pós-graduação stricto sensu. Diante dessa formação, historicamente instituída observa-se que os docentes trazem uma intensa fundamentação na racionalidade científica, pois fizeram a escolha de um curso de ciências exatas com essas características. Tal formação privilegia conhecimentos técnico-científicos em detrimento de outras áreas do conhecimento, particularmente das ciências humanas como a área de educação [Massa e D’Ávila 2013].

Em trabalho publicado no Workshop sobre Educação em Computação (WEI) na Sociedade Brasileira de Computação (SBC), os estudos de Massa [2015] demonstram as possibilidades e as limitações da formação docente no Ensino Superior em Ciência da Computação. Seus estudos foram desenvolvidos nos cursos de Análise de Sistemas e Sistemas de Informação do Campus II - Alagoinhas - da Universidade do Estado da Bahia (UNEB). Constatou-se, na pesquisa, que os professores oscilam entre o modelo transmissivo e o modelo reflexivo de acordo com seus relatos.

Verificou-se, ainda, que o docente do ensino superior diante da ausência de uma formação pedagógica adequada, utiliza sua experiência empírica ou referências de atuação observada em seus professores ao longo de sua trajetória como graduandos. Como também aponta as pesquisas de Anastasiou [2011] ao analisar a docência no ensino superior e sua trajetória. Por consequência, Massa [2015] conclui que a falta de uma formação inicial e continuada na constituição do profissional docente do ensino superior culmina na supervalorização da sua experiência de atuação profissional, bem como na empírica no exercício da docência. 
Nesse contexto, as exigências postas a carreira docente universitária em Ciência da Computação apontam apenas para formação inicial técnico científica em bacharelado e transfere a responsabilidade da formação específica para docência aos cursos de pós-graduação [Massa e D’Ávila 2013]. No entanto, os cursos de pós-graduação em computação preocupam-se em formar pesquisadores e não fornecer qualificação adequada a ação docente de maneira mais ampla.

A pesquisa de Morais et al. (2018) indica que preocupação com a formação à docência universitária em Ciência da Computação nos cursos das Regiões Norte e Nordeste, restringe-se a disciplina de Metodologia do Ensino Superior (Didática do Ensino Superior ou disciplina equivalente) em poucos programas de pós-graduação [Morais et al. 2018]. Esses indícios demonstram um significativo aspecto de reflexão para pensar o ensino de Ciência da Computação no Brasil, principalmente no ensino superior devido a intensa demanda de formação de profissionais que atuarão na sociedade.

\section{Metodologia}

Dando continuidade à pesquisa desenvolvida por Morais et al. (2018), neste artigo é apresentada uma pesquisa documental quantitativa nos documentos oficiais dos cursos de mestrado ou doutorado acadêmicos avaliados pela Coordenação de Aperfeiçoamento de Pessoal de Nível Superior (CAPES) na área de Ciência da Computação do Brasil. O artigo apresentado por Morais et al. (2018) trata sobre os documentos oficiais dos cursos de pós-graduação stricto sensu da área de Ciência da Computação, mas limita-se aos cursos das Regiões Norte e Nordeste do Brasil e exclui também os cursos em Instituições de Ensino Superior (IES) privadas ou estaduais, por exemplo os cursos da UEFS e da UNIFOR.

Portanto, neste artigo foram analisados os documentos de 64 PPG da área de Ciência da Computação. Foram analisados os cursos de mestrado ou doutorado acadêmico cadastrados na Plataforma Sucupira com nota entre 3 e 7. Desta pesquisa foram excluídos os cursos que ainda não foram reconhecidos (i.e., cursos autorizados), cursos que foram identificados como extintos (e.g. o doutorado multi-institucional da UFBA/UEFS/UNIFACS) e mestrados profissionais. O Quadro 1 apresenta as IES dos PPG analisados, em ordem alfabética.

Quadro 1. IES na qual PPG fizeram parte do corpus desta pesquisa.

\begin{tabular}{|c|c|c|c|c|}
\hline Cefet-RJ & UFABC & UFMG & UFRPE & UNIFEI \\
\hline FURG & UFAL & UFMS/UFG & UFS & UNIFESP \\
\hline IFCE & UFAM & UFOP & UFSC & UNIFOR \\
\hline IME & UFBA & UFPA & UFSCar-PPGCC & UNIRIO \\
\hline PUC-RIO & UFC & UFPB & UFSCar-PPGCCS & UNISINOS \\
\hline PUC/MG & UFCG & UFPE & UFSM & UNIVALI \\
\hline PUC/PR & UFES & UFPEL & UFU & UPE \\
\hline PUC/RS & UFF & UFPI & UFV & USP-ICMC \\
\hline UDESC & UFG & UFPR & UNB & USP-IME \\
\hline UECE & UFJF & UFRGS & UNESP & USP-PPGCA \\
\hline
\end{tabular}




\begin{tabular}{|c|c|c|c|c|}
\hline UEL & UFSJ & UFRJ-PESC & UNICAMP & USP-PPGSI \\
\hline UEM & UFLA & UFRJ-PPGI & UNIFACCAMP & UTFPR \\
\hline UERN/UFERSA & UFMA & UFRN & UNIFACS & --- \\
\hline
\end{tabular}

A pesquisa documental tem como objetivo buscar informações e padrões em documentos para fornecer uma resolução para um determinado problema [WAZLAWICK 2010]. Nesse sentido, para identificar se os PPG da área de Ciência da Computação do Brasil implementam disciplinas ou atividades para auxiliar a formação didático-pedagógica do docente do ensino superior foram buscados os objetivos e estruturas curriculares em regimentos, regulamentos, normas e web sites dos cursos corpus deste artigo. Para atingir este objetivo os documentos foram analisados quantitativamente, a partir das seguintes questões estabelecidas por Morais et al. (2018):

Q1. Qual é o objetivo do programa de pós-graduação?

Q2. O programa de pós-graduação oferece alguma disciplina voltada à formação docente?

Q2.1. Qual é o título dessa disciplina?

Q2.2. Essa disciplina é de caráter obrigatório?

Q3. O programa de pós-graduação oferece alguma atividade curricular voltada à formação docente (ex.: estágio docente)?

Q3.1. Quais são os tipos de atividades?

Q3.2. Essas atividades são de caráter obrigatórias?

As respostas para as questões foram tabuladas e analisadas quantitativamente. A seção seguinte apresenta os resultados da pesquisa realizada e as discussões.

\section{Resultados}

A partir da aplicação da metodologia foi possível identificar, quantitativamente, como os PPG tem implementado disciplinas e atividades para a formação didático-pedagógicas do docente do ensino superior. Pois, pode-se considerar como uma das possibilidades de oferecer aos discentes da pós-graduação uma formação à docência futura, uma vez que as áreas das ciências exatas, como é o caso da Ciência da Computação, não oportuniza experiências nesse campo de atuação. Nesse caso, o professor na área de Ciência da Computação, geralmente, torna-se docente baseado no empirismo elementar da experiência subjetiva e reproduz a gestão das aulas ministrada pelos seus professores da graduação [Imbernón 2012].

Inicialmente, foi construída uma tagcloud a partir dos objetivos de cada $\mathrm{PPG}^{1} \mathrm{e}$ realizada contagens das palavras, a Figura 1 apresenta a tagcloud. Destaca-se três palavras da tagcloud: (i) pesquisa, (ii) computação e (iii) ensino. A palavra pesquisa aparece 59 vezes nos objetivos dos PPG e por isso está em maior destaque na tagcloud. Por sua vez, as palavras computação e ensino são utilizadas nos objetivos dos PPG 43 e 28 vezes, respectivamente.

Nesse sentido, é possível identificar que nos objetivos a palavra pesquisa é mais citada que as demais. Esse resultado fortalece o que foi evidenciado por Morais et al.

\footnotetext{
1 É importante evidenciar que não foi possível identificar os objetivos dos PPG das seguintes IES: USP-IME, UFF, UPE, UFMA e FURG.
} 
(2018), que os objetivos dos PPG estão mais alinhados à pesquisa do que a formação docente dos seus estudantes. Consequentemente, não é objetivo de grande parte dos PPG formar os professores do ensino superior, conforme é recomendado pelo Parecer MEC/CESu n ${ }^{\circ}$ 977/65. Nesse contexto, é interessante resgatar que a docência no ensino superior não pode ser relegada apenas ao campo da pesquisa, precisa também centrar seus esforços as necessidades do exercício do magistério [Soares e Cunha 2010].

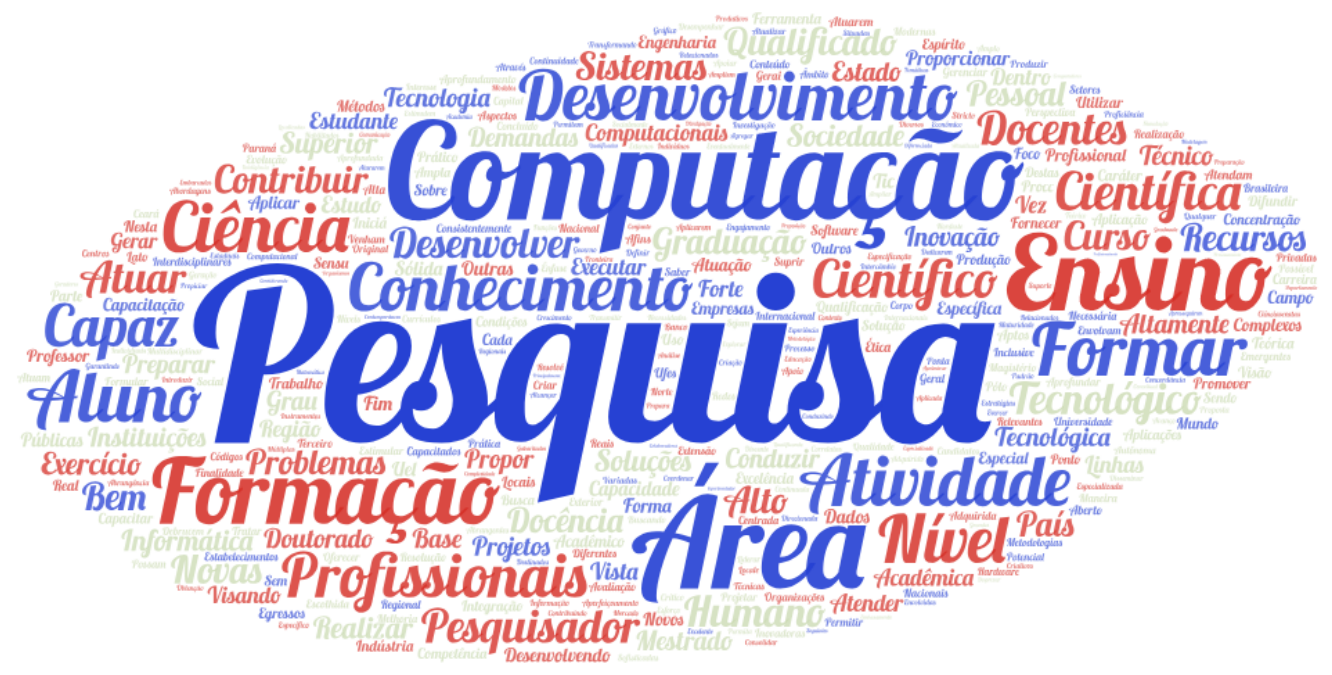

Figura 1. Tagcloud formada com as palavras contidas nos objetivos dos PPG.

Destaca-se ainda, foi identificado o objetivo de 59 dos 64 PPG pesquisados, sendo que destes encontrados, 34 expressões explicitamente o objetivo da formação de professores do ensino superior. Portanto, 57\% dos PPG da área de Ciência da Computação explicitam a formação de docentes em seu objetivo, a Figura 2 apresenta um gráfico com estes dados. Destes 34 PPG, 19 mencionam primeiro a formação docente em detrimento aos demais objetivos.

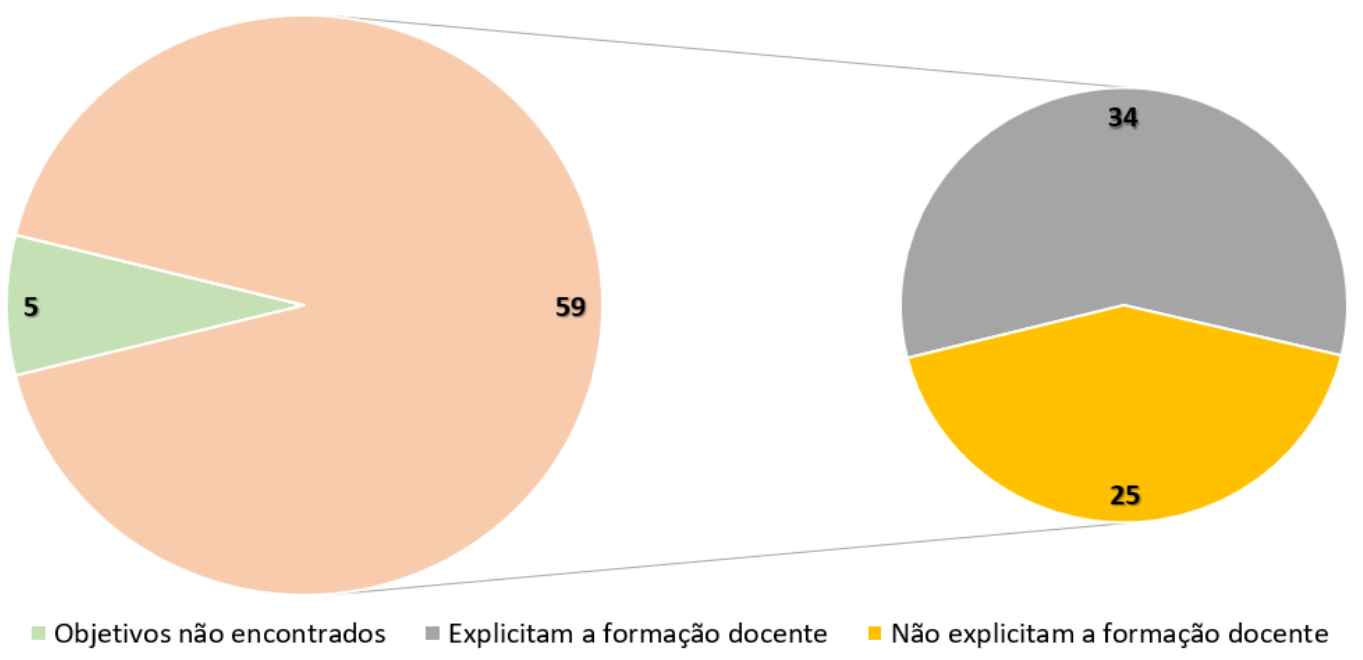

Figura 2. Gráfico com a quantidade de PPG em que os objetivos explicitam a formação docente.

A partir desses resultados, observa-se que o objetivo de grande parte dos cursos de mestrado e doutorado brasileiros da área de Ciência da Computação não estão 
alinhados ao objetivo dado pelo Parecer MEC/CESu n ${ }^{\circ}$ 977/65, que põe como primeiro objetivo a formação do professorado e como segundo objetivo o desenvolvimento de pesquisas. Isto corrobora com a pesquisa de Anastasiou [2011] e Massa [2015], que concluem que docentes no ensino superior atuam baseados nas experiências que vivenciou enquanto discente na graduação, tendo como modelo as ações de determinados professores.

Quanto ao oferecimento de disciplinas para a formação didático-pedagógica do mestrando e do doutorando, somente foram encontradas disciplinas com o objetivo da formação docente em nove $\mathrm{PPG}^{2}$, sendo que nos PPG da UFMS/UFG, UPE e USP-PPGSI a disciplina é obrigatória para mestrado e doutorado e nos PPG da UNIRIO e da USP-ICMC obrigatória somente para o doutorado. A Figura 3 apresenta estes dados em forma de gráficos.



Figura 3. Gráfico com a quantidade de PPG com disciplinas para a formação docente.

É importante destacar o PPG da UFSC, que possui uma disciplina optativa específica para tratar sobre o ensino de Engenharia de Software, a disciplina INE 410091 - Estratégias de Ensino na Engenharia de Software. Destaca-se também o PPG da USP-ICMC, em que obrigatoriamente o doutorando deve cursar uma disciplina dentre um rol com quatro. Enfatiza-se ainda que dentre os PPG de nota CAPES 6 e 7, somente os PPG da USP-ICMC e USP-IME são ofertadas disciplinas para a formação docente.

Sobre as atividades para a formação de docentes, foi possível identificar que 47 PPG estabelecem pelo menos uma atividade curricular ( $c f$. Figura 4). A grande parte dos PPG denominam essa atividade como "Estágio Docência". Entretanto, esta atividade não é obrigatória em todos os cursos, por exemplo, e, alguns PPG o Estágio Docência é obrigatório somente para estudantes de doutorado, em outros PPG a obrigatoriedade é somente para os estudantes bolsistas. Vale destacar que, apesar dos PPG da USP-ICMC (CAPES 7) e da USP-IME (CAPES 6) terem uma disciplina obrigatória de preparação

\footnotetext{
${ }^{2}$ USP-ICMC, USP-IME, UFSC, UNIRIO, USP-PPGSI, UPE, UFS, IFCE e UFSM/UFG.
} 
docente, o Programa de Aperfeiçoamento de Ensino, que é uma atividade semelhante ao Estágio Docência nos outros PPG, não é obrigatório para os seus estudantes.

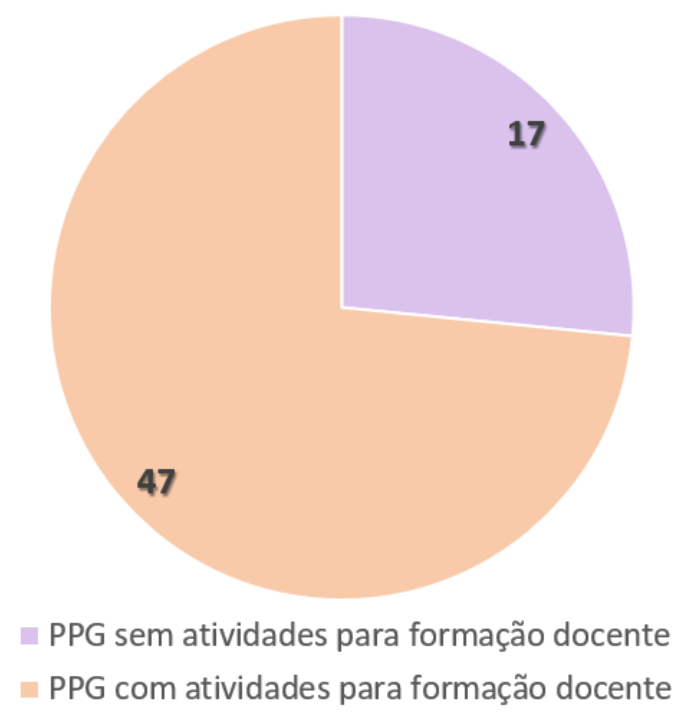

Figura 4. Gráfico com a quantidade de PPG com atividades para a formação docente.

As disciplinas relacionadas ao campo didático-pedagógico poderiam auxiliar a constituição dos saberes docentes [Tardif 2012] para atuação no ensino superior, no entanto, o que geralmente se tem são saberes experienciais constituído de maneira subjetiva. As diretrizes oriundas a pós-graduação têm sua atenção voltada à pesquisa e em muitos casos não há preocupação com as especificidades do magistério no Ensino Superior. Certamente, isso, se deve as indicações dos mecanismos de avaliação da CAPES ao ensino superior que não avalia a atuação no campo do magistério em si, e sim seus indicadores de pesquisa.

Há uma intensa necessidade de se repensar a constituição dos saberes universitários relevantes ao exercício da docência no ensino superior como aponta Cunha [2006]. No contexto, de ausência de uma formação docente universitária como se pode discutir as possibilidades de formar um professor reflexivo de sua própria prática segundo os estudos de Pimenta [2012]. Precisa-se viabilizar no ensino superior ações de formação voltada a reflexões que amplie a compreensão sobre os vários condicionantes influenciadores dos processos de ensino e de aprendizagem [Pimenta e Almeida 2011].

De acordo com os estudos de Massa e D’Avilla [2013] os docentes oriundos da Ciência da Computação devido a sua formação ter sido voltada às ciências exatas têm as reflexões sobre o fazer docente comprometida, pois com o intenso uso da racionalidade técnica em sua graduação ou pós-graduação tem limitações para refletir e modificar sobre sua prática docente. Certamente, a vivência em disciplinas ou formações diversas na pós-graduação poderiam contribuir com o fazer docente na universidade. Cabe evidenciar que existem poucos estudos que abordam a temática que trata da formação docente no ensino da Ciência da Computação, diante disso, é interessante cada vez mais aprofundar os estudos. 


\section{Considerações Finais}

Nos estudos realizados por Morais et al. (2018) no que se refere à análise dos objetivos dos PPG, identificou-se que a palavra mais mencionada foi "Computação", seguida de "Ciência" e "área". As palavras "ensino" e "pesquisa" possuem menos destaque que "Computação", "Ciência" e "área". No estudo atual apresentado, "pesquisa" continua tendo mais destaque que "ensino". Portanto, é possível identificar que os resultados identificados no artigo de Morais et al. (2018), que restringem o corpus da pesquisa para as Regiões Norte e Nordeste do Brasil e para IES federais, se expandem para os demais PPG da área de Ciência da Computação do Brasil.

É importante salientar que, apesar de também observarmos a nível nacional a priorização da pesquisa e da formação de pesquisadores sobre construção de saberes docentes na pós-graduação em Computação, na região Nordeste este fenômeno é marcadamente mais visível - visto a comparação entre os dados dessa pesquisa e aqueles apresentados por Morais et al. (2018).

No atual estudo, os dados da pesquisa assumem uma completude baseado em dados de todo Brasil e denota que as avaliações de órgãos como a CAPES centram-se suas preocupações na produtividade acadêmica em pesquisa, em detrimento de dimensões mais amplas do ensino superior. Por isso, os programas desde sua concepção colocam em destaque a pesquisa e pouco se reporta ao ensino. Vale salientar que o próprio surgimento das pós-graduação, amparado pelo Parecer MEC/CESu nº 977/65, configurou-se em um contexto com concepções de ensino tradicionais com restritas possibilidades de análise do fazer docente no ensino superior. Período que se destaca pelo surgimento da pós-graduação no Brasil em diversas áreas.

É notório que o ensino superior tem como papel essencial na condução da pesquisa em nosso país. No entanto, ainda vive suas intensas limitações em refletir sobre a condução da carreira docente no ensino superior, com possível preparação docente para atuar no magistério. Observa-se no transcurso do estudo que a constituição dos saberes docentes no ensino superior é uma necessidade urgente, devido às restritas experiências vivenciadas juntos aos programas de pós-graduação, particularmente, no ensino da Ciência da Computação.

$\mathrm{Na}$ análise realizada sobre os programas de pós-graduação no Brasil em Ciência da Computação mostra-se indícios que necessitaria de uma maior preocupação com o ensino em si, uma vez que poderia sistematizar formação de seus docentes e de seus futuros para inclusive ampliar as possibilidades de pesquisa das próprias práticas docente na universidade. Poderia se entender melhor as demandas emanadas da relação professor-aluno-conhecimento. Complica-se quando se pretende construir saberes docentes apenas no campo empírico de vivências em sala de aula sem refletir de maneira mais ampla sobre toda uma "teoria de ensino" que poderia embasar o ensino superior.

Pretende-se em estudos posteriores aprofundar o entendimento sobre o significado do fazer docente na pós-graduação por meio de coleta de dados junto aos coordenadores dos PPG em Ciência da Computação, no sentido de investigar o magistério em sua trajetória acadêmica. Além disso, pretende-se realizar investigações juntos aos estudantes de pós-graduação e professores universitários. 


\section{Agradecimentos}

Agradecemos ao Grupo de Pesquisa e Extensão Onda Digital (UFBA/CNPq). A autora Pauleany S. Morais agradece ao Instituto Federal de Educação, Ciência e Tecnologia do Rio Grande do Norte (IFRN) pela vivência de uma formação continuada por meio do pós-doutoramento, bem como ao Grupo de Pesquisa e Extensão Onda Digital da UFBA pelo acolhimento e estudos compartilhados nessa pesquisa. O autor Jean C. S. Rosa agradece o apoio financeiro por meio dos programas CAPES-DS (\#1673896) e CAPES-PDSE (\#88881.189073/2018-01).

\section{Referências}

Anastasiou, L. G. C. (2011) Processos formativos de docentes universitários: aspectos teóricos e práticos. In Pedagogia Universitária: caminhos para a formação de professores, M. I. Almeida, S. G. Pimenta (Orgs.). São Paulo: Cortez.

Brasil. (1965) Parecer MEC/CESu nº 977/65. Definição dos Cursos de Pós-Graduação. 1965.

Disponível em: http://portal.mec.gov.br/cne/arquivos/pdf/2007/parecer\%20cfe\%20977-1965.pdf. Acesso em: 13 mar. 2018.

Corrêa, K. C.; Bógus, C. M.; Anastasiou, L. G. C.; Coelho, L. A.; Dantas, L. E. P. B. T.; Rivas, N. P. P.; Neto Liguori, R.; João, S. M.; Hage, S. R. V.; Püschel, V. A. A.; Iamamoto; Y. (2011) Formação pedagógica do professor universitário: reflexões a partir de uma experiência. In Pedagogia Universitária: caminhos para a formação de professores, M. I. Almeida, S. G. Pimenta (Orgs.). São Paulo: Cortez.

Cunha, M. I. (2006) Trajetórias e lugares de formação da docência universitária: da perspectiva individual ao espaço institucional a ser realizado. São Leopoldo: Unisinos. Projeto de pesquisa. PPGEdu.

D’Ávila, C. M. (2013) Docência na Educação Superior: labirintos e saídas na construção da profissionalidade docente. In Profissão docente na educação superior, C. M. D’Ávila, I. P. A. Veiga (Orgs.). 1. ed. Curitiba, PR: CRV.

Imbernón, F. (2009) Formação permanente do professorado: novas tendências. Trad. Sandra Trabucco Valenzuela. São Paulo.

- (2011) Formação docente e profissional: formar-se para a mudança $e$ incerteza. 9. ed. São Paulo: Cortez.

. (2012) Inovar o ensino e a aprendizagem na universidade. São Paulo: Cortez.

Luckesi, C.; Barreto, E.; Cosma, J.; Baptista, N. (2012) Fazer Universidade: uma proposta metodológica. 17. ed. São Paulo: Cortez.

Massa, M. S. (2015) A formação didático-pedagógica do docente da área de computação: um estudo de caso em uma Universidade Brasileira. In Anais do $23^{\circ}$ WEI - Workshop sobre Educação em Computação. XXXV Congresso da Sociedade Brasileira de Computação (CSBC). 
; D’Ávila, C. M. (2013) O Docente do Ensino Superior da área de computação e informática e sua formação didático-pedagógica. In Profissão docente na educação superior, C. M. D’Ávila, I. P. A. Veiga (Orgs.). 1. ed. Curitiba, PR: CRV.

Matos, E. (2013) Dialética da Interação Humano-Computador: tratamento didático do diálogo midiatizado. (Tese) Doutorado. Faculdade de Educação - Universidade de São Paulo (USP).

Melo, M. A.; Moraes, L. C. S.; Nascimento, I. V.; Bonfim, M. N. B. (2013) A formação pedagógica para a docência na Educação Superior: estudos sobre os egressos de um curso de especialização. In Profissão docente na educação superior, C. M. D’Ávila, I. P. A. Veiga (Orgs.). 1. ed. Curitiba, PR: CRV.

Morais, P. S.; Rosa, J. C. S.; Marinho, A. R. S.; Matos, E. (2018) Formação Docente na Pós-Graduação Stricto Sensu em Ciência da Computação: um recorte das regiões Norte e Nordeste. In Anais do $26^{\circ}$ Workshop sobre Educação em Computação (WEI). XXXV Congresso da Sociedade Brasileira de Computação (CSBC). p. 231-245.

Pimenta, S. G. (2012) Professor reflexivo: construindo uma crítica. In Professor reflexivo no Brasil: gênese e crítica de um conceito, S. G. PIMENTA, E. Ghedin (Orgs.). 7 ed. São Paulo: Cortez.

; Almeida, M. I. (2011) Docência universitária: passos de um percurso formativo. In Pedagogia Universitária: caminhos para a formação de professores, M. I. Almeida, S. G. Pimenta (Orgs.). São Paulo: Cortez. 2014.

; Anastasiou, L. G. C. Docência no Ensino Superior. 5 ed. São Paulo: Cortez,

Santos, B. S. A universidades no século XXI: para uma reforma democrática e emancipatória da Universidade. 3. ed. São Paulo: Cortez, 2011.

Tardif, M. Saberes docentes e formação profissional. 14 ed. Petrópolis, RJ: Vozes, 2012.

Wazlawick, R. S. (2010) Uma Reflexão sobre a Pesquisa em Ciência da Computação à Luz da Classificação das Ciências e do Método Científico. Revista de Sistemas de Informação da FSMA, n. 6. p. 3 - 10. 